\title{
CONVERGENCIAS Y DIVERGENCIAS ENTRE LOS SISTEMAS EUROPEO E INTERAMERICANO DE DERECHOS HUMANOS*
}

\section{Laura Alicia Camarillo Govea**}

Fecha de recepción: 1 de marzo de 2015

Fecha de evaluación: 5 de junio de 2015

Fecha de aprobación: 15 de octubre de 2015

Artículo de investigación

DOI: http://dx.doi.org/10.18359/prole.1680

Forma de citación: Camarillo, L. (2016). Convergencias y divergencias entre los sistemas europeo e interamericano de derechos humanos. Revista Prolegómenos Derechos y Valores, 19, 37, 67-84. DOI: http://dx.doi.org/10.18359/prole.1680

\section{Resumen}

El artículo presenta un estudio analítico sobre la relación entre los sistemas europeo e interamericano de derechos humanos, dando especial relevancia al diálogo existente entre ambos tribunales. El problema de investigación busca identificar cuáles son los puntos de conexión y divergencias entre los dos escenarios de protección de derechos humanos. La metodología es la del análisis comparativo y doctrinal respecto a sendos órganos, predominantemente desde la óptica de su estructura orgánica y funciones. Se pretende destacar que en la jurisprudencia ha habido una relación que en general, propicia la Corte Interamericana que recoge en algunos casos, las aportaciones de su homólogo el tribunal europeo y que logran insertarse en sus propias sentencias.

\section{Palabras clave:}

Derechos humanos, sistema europeo, sistema interamericano, diálogo, Corte Interamericana, tribunal europeo.

* Artículo de investigación que se enmarca en el proyecto de investigación "Aportaciones del Tribunal Europeo a la Corte Interamericana de Derechos Humanos", inscrito en la Coordinación de Posgrado e Investigación de la Universidad Autónoma de Baja California, Mexicali, México (2012).

** Doctora en Derecho por la Universidad de Castilla-La Mancha, Toledo, España, tesis con mención sobresaliente cum laude. Magíster en Asuntos Internacionales por la Universidad Autónoma de Baja California, especialista en Derechos Fundamentales por la Universidad de Castilla-La Mancha, certificación de enseñanza en Derechos Humanos por el Centro Internacional para la Enseñanza del Derechos Humanos del Institut International des Droits de l'Homme, Estrasburgo, Francia. Actualmente es profesora de tiempo completo en la Facultad de Derecho Tijuana de la Universidad Autónoma de Baja California, donde imparte Derecho Internacional de los Derechos Humanos y Derecho Internacional Público. Correo electrónico: govea@uabc.edu.mx 


\title{
CONVERGENCES AND DIVERGENCES BETWEEN EUROPEAN AND INTER AMERICAN HUMAN RIGHTS SYSTEMS
}

\begin{abstract}
Summary
This article submits an analytic study about the relationship between European and Inter American human rights systems, giving special relevance to the existing dialogue between both tribunals. The research problem tries to identify the connection points and divergences between the two sceneries of protection of human rights. The methodology is the one of comparative and doctrinal analysis regarding both systems, predominately from the view of its organic structure and functions. It is intended to highlight the fact that there has been, in jurisprudence, a relationship that allows the implementation of certain contributions from the European tribunal to the Inter American Court.
\end{abstract}

\section{Keywords:}

Human rights, European system, Inter American system, dialogue, Inter American Court, European tribunal.

\section{CONVERGÊNCIAS E DIVERGÊNCIAS ENTRE O SISTEMA EUROPEU E O INTERAMERICANO DE DIREITOS HUMANOS}

\begin{abstract}
Resumo
Este artigo busca apresentar um estudo analítico entre a relação entre o sistema europeu $e$ o interamericano de direitos humanos, com um enfoque especial ao diálogo existente entre estes tribunais. O objeto de investigação principal pretende identificar quais os pontos de conexão e divergências entre ambos cenários com relação à proteção dos direitos humanos. A metodologia trás uma análise comparativa e doutrinal com respeito a estes órgãos, com uma visão predominante de sua estrutura orgânica e funções. Pretende-se destacar a existência de uma relação entre jurisprudência de ambas, que propicia à Corte Interamericana reconhecer em alguns casos, aportes homólogos no tribunal europeu que acabam por serem integradas em suas sentenças.
\end{abstract}

\section{Palavras-chave:}

Direitos humanos, sistema europeu, sistema interamericano, diálogo, Corte Interamericana, tribunal europeu.

\section{Introducción}

El presente artículo forma parte de la investigación "Aportaciones del Tribunal Europeo a la Corte Interamericana de Derechos Humanos", que pretendió estudiar la influencia y diálogo entre ambos tribunales, en específico las contribuciones jurisprudenciales del tribunal europeo a la Corte Interamericana. En ese tenor, el trabajo que aquí se suscribe tiene como objeto identificar los puntos de conexión y disimilitudes entre ambos sistemas de protección de derechos humanos. Para lograr este propósito, la metodología consistió en realizar un análisis comparativo eminentemente 
documental de las estructuras formales de uno y otro tribunal.

Los dos sistemas representan una forma de protección de derechos en el plano internacional y surgieron en escenarios políticos distintos. No son tampoco los únicos tribunales internacionales en la materia, sin embargo, constituyen dos hitos que a través de su jurisprudencia enriquecen la lectura de los derechos humanos.

Habría que plantearse entonces, y en ello, una de las razones de la pertinencia de este estudio, cuáles son las diferencias o similitudes de estos tribunales de derechos humanos. Este análisis permite entonces identificar en qué pueden nutrirse ambos órganos y qué les distancia. Puede partirse de la premisa fundamental de que entre estos dos sistemas existe un diálogo, cierto es que la doctrina toma nota de la plática entre constituciones y tribunales internacionales; sin embargo, resulta válido identificar los puntos de conexión entre estos dos marcos de protección de derechos humanos, máxime cuando son los escenarios más avanzados en la tutela internacional de derechos.

El Convenio Europeo guarda ciertas similitudes con la Convención Americana sobre Derechos Humanos (CADH), no obstante,

[...] el desarrollo del sistema interamericano siguió un camino distinto del de su contraparte europea. Aunque la estructura institucional superficialmente similar y las disposiciones normativas son en muchos aspectos semejantes, las condiciones en las que ambos sistemas evolucionaron fueron radicalmente diferentes.

Dondero (2000) señala que en el Consejo de Europa, los gobiernos militares y otros tipos de autoritarismo han sido escasos y breves; mientras que en América Latina casi fueron la norma, hasta los cambios que se iniciaron en los ochenta, esta situación tiene un efecto sustantivo en el actual funcionamiento de ambos sistemas $y$, consideramos, es un factor decisivo en lo que concierne al Sistema Interamericano de Derechos Humanos (SIDH), puesto que el modo en que funciona hoy por hoy la Corte y Comisión interamericanas, se justifica a partir de los antecedentes históricos del propio sistema, a saber: de la creación de la Organización de los Estados Americanos (OEA) y muy particularmente la forma en que la Comisión Interamericana y la Corte empezaron a funcionar.

El origen de los dos sistemas dista uno de otro, empero podemos identificar convergencias y divergencias entre ellos, tales como: competencias, facultades, aspectos procesales, reparaciones, etc. (Ambos \& Böhn, 2013); por otro lado, debemos reconocer que hay una influencia del sistema europeo en el interamericano y viceversa (aunque creemos predomina la influencia europea sobre el SIDH) y que se manifiesta de distintas maneras, sobre todo, a través de su jurisprudencia. Nos atrevemos a decir que existe un diálogo jurisprudencial, pero que en las sentencias de la Corte Interamericana queda prueba de la amplia presencia de los criterios jurisprudenciales europeos, aunque ello amerite un estudio y análisis más vasto que excede el objeto de la investigación en la que este artículo se inserta.

Por último, es importante analizar los órganos que le integraron, las funciones que cada tribunal tiene, los derechos humanos protegidos en ambas convenciones, la figura de la hoy extinta Comisión Europea y su actual homóloga interamericana, entre otros.

\section{A. Los sistemas europeo e interame- ricano de derechos humanos, aproximaciones comparativas}

Hay algunos estudios comparativos de los sistemas europeo e interamericano de protección de los derechos humanos ${ }^{1}$ donde se ha realizado un análisis para identificar los puntos de encuentro entre ambos sistemas, tal como señala Úbeda Amaya, "hay un paralelismo innegable

1 Consúltese Fix-Zamudio (2000), Revenga y Garcés (2008) y Acosta (2008). 
e influencias recíprocas tanto en los textos de los convenios en sí como en la jurisprudencia" (2007, p. 55), y en especial cobra significado porque frente a esas similitudes también es verdad que una de las diferencias más claras es la relativa al rol de los individuos en sendas cortes de derechos humanos.

Fix-Zamudio (2008) efectúa un análisis comparativo a partir de la integración de los órganos del sistema europeo en su estructura original, a saber: Comisión Europea, Corte Europea de Derechos Humanos y Comité de Ministros del Consejo de Europa; y luego la estructura actual del sistema interamericano que no ha sufrido modificación como sí sucedió en el sistema europeo, esto es: Comisión Interamericana de Derechos Humanos y Corte Interamericana de Derechos Humanos.

Otros autores como Londoño, indican que el mecanismo de protección europeo era un "mecanismo tripartito de control" (2005, pp. 89), por cuanto al funcionamiento de sus entonces tres entes. Pastor Ridruejo (2007) por ejemplo, planteaba incluso un tema que sin denostar el comparativo, proponía un estudio más profundo, determinar el valor específico de los tribunales internacionales en cada uno de estos continentes.

La doctrina ha hecho el análisis comparativo desde diversas ópticas, su propósito es identificar la forma y funcionamiento de ambos sistemas de protección de derechos humanos. Para alcanzar ese fin, revisaremos los sistemas, aquello relativo a su estructura formal, a las funciones que uno y otro mecanismo ofrece. Luego, el efecto de las sentencias, modalidades de reparación y la jurisprudencia de los dos tribunales.

En esos términos, el sistema europeo con mayor experiencia en gran medida por su antigüedad, descansa en el Convenio Europeo de Derechos Humanos que con sus múltiples reformas sentaba las bases en 1950 de un instrumento internacional vinculante, cuyo objetivo primordial fue precisamente la protección internacional de los derechos humanos, con la singularidad de que a través de un tribunal (Corte Europea) se regularía esa protección que en un inicio funcionó de la mano de la Comisión Europea. "Después de la Segunda Guerra Mundial, las declaraciones, los pactos y tratados relativos a la protección de los derechos humanos proliferan" (Úbeda, 2007, p. 209). Para García y Santolaya, el Convenio Europeo tiene tres fundamentos "el régimen político democrático, un concepto común de derechos y la voluntad de garantizar conjuntamente su respeto" $(2005$, p. 826$)$.

En el escenario internacional el Convenio sería punta de lanza y referencia obligada para América, y se convirtió no solo en el instrumento más importante y exitoso del sistema de protección internacional de los derechos humanos sino, como indican Janis y Kay (2008), una de las más avanzadas formas de procesos legales internacionales. Su trascendencia, podemos concretar, radica en su sistema de garantía y en el papel del tribunal europeo (Díaz, 2011).

El actual Convenio Europeo en su esencia es el mismo que el de 1950, aunque se complementa en su cuerpo normativo con diversos protocolos adicionales. Algunos de estos protocolos han desarrollado o extendido los derechos protegidos por la Convención, y otros han introducido reformas estructurales o de procedimiento (Fix-Zamudio, 2008), como lo fueron los protocolos 11 y 14 , por lo que hace a la ampliación de derechos; Protocolo 1, que incluye la protección a la propiedad (art. 1), derecho a la instrucción (art. 2) y derecho a elecciones libres (art. 3); Protocolo 4, que comprende la libertad de circulación (art. 4); Protocolo 7, el cual abarca el derecho a un doble grado de jurisdicción penal (art. 2) y el derecho a indemnización en caso de error judicial (art. 7); Protocolo 12, que hace una prohibición general de discriminación (art. 2); Protocolo 13, que trata de la abolición de la pena de muerte (art. 1), entre otros. Después surgen protocolos al Convenio Europeo de carácter procesal, como lo es el Protocolo 11, lo afirmamos así en la medida que este último formalizaría el ius standi del individuo ante el tribunal europeo.

Afirma Fix-Zamudio (2008) que el Convenio Europeo se ha visto reforzado, en lo que se 
refiere a derechos humanos agregados y a las enmiendas también trascendentales derivadas de los protocolos como el 11, que suprimió la figura de la Comisión Europea para dar plena capacidad procesal a los peticionarios, ius standi (las disposiciones de los protocolos 2, 3, 5 y 8 se sustituyeron por el Protocolo 11, el Protocolo 9 quedó derogado y el 10 quedó sin objeto).

En cuanto a la Convención Americana ${ }^{2}$ esta surge diez años después de la Comisión Interamericana, dato histórico interesante inclusive si se compara con el origen del sistema europeo que nace con el Convenio Europeo; este instrumento prácticamente entró en vigor treinta años antes de la Convención Americana.

[...] el primero, el pionero, guiará, servirá de referente directo al segundo, siendo su modelo formal , pero el "efecto espejo" no es solo de Europa hacia América, y la Convención Americana desarrollará a su vez una garantía internacional de los derechos humanos que se convertirá en un modelo, en el sentido material del término, de su homólogo europeo (Úbeda, 2007, p. 237).

Ambos sistemas al día de hoy pueden complementarse, es válido sostener que hay una influencia recíproca, reflejada particularmente en las convenciones y en la interpretación jurisprudencial de sendos tribunales internacionales respecto de los derechos humanos en ellos consagrados, sin duda, estas herramientas son los grandes pilares de sus respectivos sistemas de protección de derechos humanos.

\section{B. Los derechos protegidos en ambas convenciones}

En esta línea de análisis comparativo que nos planteamos, es de primer orden atender a los derechos humanos contemplados en los dos Convenios, ambos tienen su propio catálogo. Para Dondero (2000) un rasgo distintivo entre

2 Véase para un análisis de los derechos humanos de la Convención Americana inter alia, Feldman (2006). dichos mecanismos es que el Convenio Europeo, a diferencia de la Convención Americana, incorporó en un solo instrumento los derechos garantizados y los medios para protegerlos.

Además, la Convención Americana recoge algunos derechos que en stricto sensu no aparecen en el Convenio Europeo, como lo es el reconocimiento a la personalidad jurídica, el derecho al nombre, derechos de los niños, derecho a la nacionalidad y desarrollo progresivo.

El Convenio Europeo mediante sus protocolos "recoge" algunos derechos que su homólogo americano ya consagra en el documento original: derecho a la indemnización (Protocolo 7), a la propiedad privada (Protocolo 1), a la libertad de circulación (Protocolo 4) y a elecciones libres (Protocolo 1); por su parte, la Convención Americana consagra el derecho de rectificación o respuesta que no existe de manera idéntica en el Convenio Europeo y sucede igual con el derecho a la instrucción, protegido en el Protocolo 7 europeo que no existe como tal en la Convención Americana.

La Convención Americana es a nuestro juicio, el instrumento internacional de protección de derechos humanos más importante de América, en su cuerpo se observa una clasificación de los derechos civiles y políticos, y luego abre capítulo especial a los derechos económicos, sociales y culturales (art. 26 desarrollo progresivo), este último signo distintivo frente al Convenio Europeo que es oportuno analizar, el artículo 26 de la Convención Americana, se encuentra vinculado directamente al Protocolo de San Salvador ${ }^{3}$, que de forma más amplia desarrolla los derechos económicos, sociales y culturales.

Tratándose de protocolos, a diferencia del sistema europeo que ha recurrido a ellos con el objeto de extender derechos de modo muy puntual, en el sistema interamericano han tenido una

3 Protocolo Adicional a la Convención Americana sobre Derechos Humanos en materia de Derechos Económicos, Sociales y Culturales. 
función relativamente distinta: el artículo 77 de la Convención Americana establece la posibilidad de inclusión de nuevos derechos instrumentando los protocolos adicionales y aunque, en efecto así lo ha hecho, estos son al menos en los casos actuales, herramientas que adicionan de manera casi independiente otros derechos (en materia de derechos económicos, sociales y culturales).

El citado Protocolo de San Salvador es un "catálogo abierto" para los derechos económicos, sociales y culturales donde los Estados se comprometen a adoptar las medidas necesarias para que "progresivamente" se alcancen estos, pero que no forman parte directa de aquellos derechos susceptibles de violación para efectos de ser sometidos a la Corte Interamericana ${ }^{4}$.

Es decir, la Corte Interamericana solo conoce de violación de derechos humanos protegidos en la Convención y no así de los derechos que se consignan en los protocolos, tales como el Protocolo de San Salvador 5 y el protocolo a la Convención Americana relativo a la abolición de la pena de muerte (con semejanzas al Protocolo 6 del Convenio Europeo relativo a la abolición de la pena de muerte), salvo en el caso que establece el artículo 19.6 del Protocolo de San Salvador que expresa:

En el caso de que los derechos establecidos en el párrafo a) del artículo 8 y en el

4 La Corte Interamericana abordó los derechos económicos, sociales y culturales mediante el artículo 26 de la Convención Americana, en casos como Suárez Peralta vs. Ecuador y "Cinco Pensionistas" vs. Perú, entre otros. Los jueces Sergio García Ramírez y Eduardo Ferrer Mac-Gregor emitieron votos haciendo alusión a aquellos derechos, adicionalmente el Protocolo de San Salvador en su artículo 19.6 indica que: "En el caso de que los derechos establecidos en el párrafo a) del artículo 8 y en el artículo 13 fuesen violados por una acción imputable directamente a un Estado parte del presente Protocolo, tal situación podría dar lugar, mediante la participación de la Comisión Interamericana de Derechos Humanos, y cuando proceda de la Corte Interamericana de Derechos Humanos, a la aplicación del sistema de peticiones individuales regulado por los artículos 44 a 51 y 61 a 69 de la Convención Americana sobre Derechos Humanos".

5 Supra nota 3. artículo 13 fuesen violados por una acción imputable directamente a un Estado parte del presente Protocolo, tal situación podría dar lugar, mediante la participación de la Comisión Interamericana de Derechos Humanos, y cuando proceda de la Corte Interamericana de Derechos Humanos, a la aplicación del sistema de peticiones individuales regulado por los artículos $44 \mathrm{a}$ 51 y 61 a 69 de la Convención Americana sobre Derechos Humanos (Protocolo de San Salvador, 1988).

En general, ambos catálogos de derechos humanos son muy similares y tal como se afirmó, en cada sistema se han logrado insertar otros derechos vía protocolos facultativos.

\section{Las comisiones europea e interamericana}

Si bien la Comisión Europea desapareció en 1998, tuvo semejanzas con la Comisión Interamericana de Derechos Humanos aun y en escenarios distintos. Fix-Zamudio aseveró que las comisiones tanto europea como interamericana son órganos cuasi jurisdiccionales que reciben peticiones individuales, realizan funciones prejudiciales, formulan recomendaciones y eventualmente remiten algunas de esas peticiones a la decisión de la respectiva Corte (2000, pp. 507-533).

En efecto, la labor de ambas atendió a contribuir con las cortes respectivas a canalizar las demandas que les llegarían a estas, con independencia de que desde el origen del sistema europeo ya se vislumbraba un tribunal de acceso directo para el individuo. La Comisión Europea hasta 1998, formaba parte del sistema europeo de derechos humanos, es preciso hacer una división entre el régimen original establecido por el Convenio Europeo y aquel establecido con motivo del Protocolo 11 que entró en vigor el primero de noviembre de 1998. En el caso de la Comisión Europea, se integraba por un experto, electo por la Asamblea Parlamentaria del Consejo de Europa y por cada uno de los Estados que hubieran 
firmado el Convenio Europeo y que estuvieran incorporados al Consejo antes mencionado.

La Comisión Europea se pensó podía ser un filtro al momento de admitir las demandas, pero para Viana (2008) parte de la doctrina considera que ejercía funciones judiciales en lo que respecta a sus decisiones sobre la admisibilidad de las demandas, también funciones diplomáticas o de mediadora en el marco de los procesos de arreglo amistoso y funciones cuasi judiciales cuando profería el informe de fondo de los casos.

Ahora, la Comisión Europea debía remitir su informe al Comité de Ministros, que decidía finalmente si en el plazo de tres meses el asunto no era llevado al tribunal por los únicos sujetos legitimados para hacerlo: la propia Comisión, el Estado de la nacionalidad de la víctima, el Estado demandante o el Estado demandado (Díaz, 2004). La Interamericana en cambio sigue funcionando como la antesala de la Corte Interamericana, ciertamente ha sufrido algunas reformas, en específico a través de sus reglamentos (el más reciente de 2013); incluso así, mantiene sus funciones casi intactas, pues realizaría una tarea casi que de fiscalía, claro que en el plano internacional la queja presupone la supuesta violación de los derechos humanos protegidos por la Convención Americana y otros instrumentos del sistema interamericano. En esencia, la Comisión Interamericana tiene la función principal de promover la observancia y la defensa de los derechos humanos.

Es pues la propia Convención Americana, la que señala en su parte III que los medios de protección de los derechos son mediante dos órganos competentes: la Comisión Interamericana y la Corte Interamericana. Resulta oportuno decir que un aspecto que diferencia a ambos tribunales es lo relativo al trabajo que ejecutaron en su momento la Comisión Europea y la Comisión Interamericana, al margen de la todavía existencia de esta última.

[...] en Europa hasta la existencia de la Comisión Europea tenía (con algunas raras excepciones) la cooperación de los gobiernos, en cambio la CIDH tuvo que lidiar con problemas muy diferentes: detenciones arbitrarias, desapariciones forzadas y en ese sentido los Estados más como antagonistas que como socios (Robertson, 1981, pp. 50).

Aunado a que la génesis de la Comisión Interamericana data diez años antes de la creación de la Corte Interamericana, y aunque fue un órgano esencial en la reconstrucción de algunas democracias latinoamericanas, tiene peso histórico por ello, que contribuye a mantener el statu quo del sistema interamericano y la reticencia a cambios que podrían presentarse en favor del ius standi del individuo, por citar un ejemplo.

\section{Los tribunales europeo e intera- mericano, su valiosa aportación y sus diferencias}

El Convenio Europeo y la Convención Americana dieron vida a dos de los tribunales internacionales de derechos humanos más importantes de la actualidad, sendas cortes reflejan ciertas diferencias en cuanto a su estructura. Una de las características decisivas en el vigente funcionamiento de los dos tribunales, es la naturaleza de tribunal permanente que tiene el europeo vis a vis el interamericano, este elemento sin duda es relevante de cara al óptimo funcionamiento del tribunal europeo, situación que se vincula a aspectos administrativos y financieros que sin duda inciden en el actuar de dicho escenario, el título II del Convenio Europeo se refiere a la creación del propio tribunal que funcionará de manera permanente (art. 19) y anota que se compondrá del mismo número de jueces que conforman las altas partes contratantes.

En ese sentido resalta una diferencia adicional a la Corte Interamericana, en tanto en Europa la Corte entonces se compondrá de 47 jueces, mientras que su homóloga interamericana, cuenta con siete jueces, nacionales todos de los Estados miembros de la OEA. Frente a la desaparición de la Comisión Europea, el tribunal europeo de 
conformidad con lo expresado en los artículos 26 al 28 del Convenio Europeo, se organiza en la gran sala, salas, comités y jueces únicos que distribuyen sus funciones para dar atención a las demandas que se presentan. Por su parte, la Corte Interamericana no tiene más allá que los jueces señalados y una secretaría del tribunal, lo anterior según se estipula en los artículos 3 al 8 del Estatuto de la Corte Interamericana.

Además de esta serie de disimilitudes entre los tribunales en comento, como es bien sabido, la Corte Interamericana despliega su competencia contenciosa a partir de un reconocimiento expreso de aquellos Estados americanos que así lo estimen conveniente. El artículo 62 de la Convención Americana indica que deberá hacerse la declaración de reconocimiento obligatorio y sin convención especial, y en condiciones tales como por plazo determinado, para casos concretos.

Una de las críticas que se le hace al sistema quizá sobre todo de aquellos que toman como referencia al europeo para "valorarlo", es precisamente esta facultad discrecional que tiene cada Estado para decidir si se somete a la jurisdicción de la Corte. En esos términos, a día de hoy la Corte es realmente una latinoamericana, en tanto la ausencia de algunos Estados, tales como Estados Unidos y Canadá.

Comprendemos que esta circunstancia puede generar algún debate, incluso debilitar al propio tribunal interamericano, y desde la perspectiva europea, esto no tendría mucha razón, esa "fragmentación de la Corte Interamericana" puede ser objeto de crítica, pues la protección de la dignidad humana y promoción de los derechos humanos de ninguna forma puede ser parcial, empero, se refleja en este rubro las marcadas diferencias entre los países del norte de América y el resto, siendo los primeros parte de aquellos que no reconocen competencia de la Corte Interamericana ${ }^{6}$.

6 Estados Unidos y Canadá, aunque fuera de la competencia contenciosa de la Corte se encuentran también: Santa Lucía, Guyana, Antigua y Barbuda, San Cristóbal
Al contrario del continente europeo totalmente integrado, América nunca se ha vislumbrado así, los procesos de integración regional no son siquiera comparables. De acuerdo con Viana:

[...] con el resurgimiento de bloques de derecha e izquierda en el continente [americano] y la resurrección mediática de ciertas luchas sociales, el sistema interamericano verá llegar, pronto, una nueva época en todo diferente a lo que ha sucedido hasta hoy, $y$, por supuesto, lejos de las coordenadas de desarrollo que podrían haber marcado la historia del Convenio Europeo y su Comisión Europea (2008, pp. 16-69).

Buerguenthal y Douglas reconocen también la necesidad de convertir a la Corte IDH en un tribunal permanente, pero dan cabida a que:

[...] esa es una cuestión política que dependerá de los Estados frente a las obligaciones que sí tiene en efecto la Corte IDH y la propia $\mathrm{CIDH}$ de ser funcionales, ese [la integración de todos] considero que no depende de ellos (1998, p. 539).

A pesar de que tal afirmación data de 1998, la situación se mantiene igual. Y es que en ese sentido, existe uniformidad de criterios, todos quieren un tribunal permanente, al respecto comenta Cançado (2001):

[...] la nécessité d'universaliser le système interaméricain par le biais de la ratification de la Convention américaine ou de l'adhésion à celle-ci par tous les États membres de l'Organisation régionale ainsi que par le biais de l'acceptation de la compétence obligatoire de la Court interaméricaine en matière contentieuse par tous le États parties à la Convention (pp. 208).

\footnotetext{
y Nieves, San Vicente y las Granadinas, Dominica y Bahamas y más recientemente Venezuela, descontando la ausencia de Cuba de la OEA. Véase: http://www.oas. org/es/cidh/
} 
En la serie de reformas que ha sufrido el sistema interamericano y las reflexiones que ha generado esta, destacan los resultados que se dieron en la Asamblea General de la OEA (2000 y 2001) y Cumbre de las Américas en 2001, que entre otras cosas planteaban un tribunal permanente, la evolución paulatina hacia una corte y comisión permanentes. Afirma Ventura (2003) que con el fin de poder atender debidamente y con celeridad un mayor número de casos, el paso final debería ser una corte permanente, en la que sus jueces devengarían un salario, tendrían la obligación de residir en la sede y tendrían incompatibilidades, de acuerdo con el Estatuto, para ejercer otras funciones.

Para Cançado "tanto la Corte Interamericana como el tribunal europeo, han establecido límites al voluntarismo estatal, han protegido la integridad de las convenciones respectivas sobre derechos humanos y la primacía de consideraciones de ordre public" (2007, p. 17). Ahí su pertinencia, con convergencias y divergencias, contribuyen a mejor protección de derechos humanos.

\section{E. Funciones jurisdiccionales y consultivas de ambos tribunales}

\section{La función contenciosa de los tribunales europeo $e$ interamericano}

Los cargos principales de los tribunales interamericano y europeo en materia de análisis, guardan algunas distancias que es cardinal revisar. En primer lugar, la Corte Interamericana,

[...] tiene carácter opcional o facultativo para los Estados partes, en tanto solo puede realizarse cuando los propios Estados reconozcan de manera expresa como obligatoria la competencia de la Corte, ya sea en forma incondicional, o bajo condición de reciprocidad, por un plazo determinado o para casos específicos (Novak, 2002, p. 649.)

Esta "peculiaridad" del sistema interamericano y en particular de la Corte Interamericana, ge- nera que, en la práctica, algunos Estados no le reconozcan su competencia contenciosa o que habiéndolo hecho, denuncien la Convención Americana, como recientemente sucedió con Venezuela. La Corte Interamericana a través de su opinión consultiva 1/82 "Otros tratados" apuntó:

[...] que ella es ante todo y principalmente, una institución judicial autónoma que tiene competencia para decidir cualquier caso contencioso relativo a la interpretación y aplicación de la Convención [...] la Corte representa, además el órgano con mayor poder conminatorio para garantizar la efectiva aplicación de la Convención (Corte Interamericana, 1982, párr. 22).

Contrario a lo que sucede en el sistema interamericano, el tribunal europeo extiende su competencia a todos aquellos Estados parte de la Unión Europea, así, estamos frente a un instrumento cuya competencia no se suscribe a reconocimiento expreso por parte de los Estados; sin embargo, podemos afirmar que al igual que la Corte Interamericana tiene la función de interpretar en su caso, el Convenio Europeo.

\section{La función consultiva de la Corte Inte- ramericana frente a la europea}

En lo que atañe a las funciones consultivas de los tribunales americano y europeo, hemos de aludir al fundamento convencional en cada caso para su posterior análisis, así, el artículo 47 del Convenio Europeo, faculta al tribunal europeo para emitir opiniones consultivas desde el presupuesto siguiente: a solicitud del Comité de Ministros y cuando se refiera a cuestiones jurídicas relativas a la interpretación del Convenio y de sus protocolos. Sin embargo, el Convenio Europeo va más allá y precisa las condiciones o límites para la emisión de estas, esto es, no podrán apuntar ni a las cuestiones que guarden relación con el contenido o la extensión de los derechos y libertades enunciados en el título I del Convenio y de sus protocolos, ni a los demás asuntos de los que el tribunal o el Comité de Ministros pudieran conocer de resultas de la presentación 
de un recurso previsto por el Convenio. Luego, una vez que el Comité la(s) solicite, se adoptará por mayoría de los representantes con derecho a intervenir en el Comité, según establece el artículo 47 del Convenio Europeo.

Frente a esta serie de requisitos o condiciones queda más claro porqué en el sistema europeo poco se ha recurrido a las opiniones consultivas y porqué estas son escasas respecto a lo que sucede en el sistema interamericano.

El margen restrictivo de las opiniones consultivas del tribunal europeo de Derechos Humanos es desafortunado. El procedimiento de opiniones consultivas bajo la Convención Americana [...] el cual está abierto a los miembros de la OEA, ha probado ser una herramienta particularmente fructífera de jurisprudencia bajo la Convención (Ovey \& White, 2002, p. 10).

En la práctica, las funciones del tribunal europeo son predominantemente contenciosas, aunque ambas funciones están reguladas en el Convenio Europeo, Novak (2002) sostiene que aquel tribunal no ha desarrollado sus funciones consultivas si se le compara con la Corte Interamericana.

En cuanto a las opiniones consultivas de la Corte Interamericana regladas en el artículo 64 de la $\mathrm{CADH}$, permite a los Estados miembros de la OEA incluso sin reconocimiento del otro cometido de la Corte Interamericana (competencia contenciosa), consultar acerca de la interpretación de la $\mathrm{CADH}$ o de otros tratados concernientes a la protección de los derechos humanos en los Estados americanos.

Así mismo, podrán consultarla, en lo que les incumbe, los órganos enumerados en el capítulo $\mathrm{X}$ de la Carta de la OEA, reformada por el Protocolo de Buenos Aires. Además la Corte puede, a solicitud de un Estado de la OEA, emitir opinión acerca de la compatibilidad entre cualquiera de sus leyes internas y los mencionados instrumentos internacionales. La Corte ha sostenido que el artículo 64 confiere la más amplia función consultiva que se haya confiado a tribunal internacional alguno hasta el presente; pone de manifiesto el importante poder de apreciación del tribunal para valorar las circunstancias de cada especie frente a los límites genéricos que la Convención fija para su función consultiva. Estas se refieren a que

[...] la función consultiva de la Corte [...] tiene por finalidad coadyuvar al cumplimiento de las obligaciones internacionales de los Estados Americanos en lo que concierne a la protección de los derechos humanos, así como al cumplimiento de las funciones que en este ámbito tienen atribuidos los distintos órganos de la OEA (opinión consultiva 1/82).

La Corte no obstante, dejó sentado que en determinadas condiciones, podría abstenerse de responder una solicitud de consulta. Ello ocurre, claro está, si la consulta no se refiere a la interpretación de tratados en que esté directamente implicada la protección de los derechos humanos en un Estado miembro del sistema interamericano. Nikken (2003) sostiene que la Corte agregó otro supuesto que se vincula con una apreciación teleológica de su función consultiva, que debe orientarse a fortalecer el sistema y a coadyuvar al cumplimiento de las obligaciones internacionales de los Estados americanos en lo que atañe a la protección de los derechos humanos, así como al cumplimiento de las funciones que en este escenario tienen atribuidas los distintos órganos de la OEA.

La Corte ha dicho que dentro del ejercicio de su función consultiva, lo esencial era interpretar las normas internacionales atinentes a derechos humanos aplicables en cualquier Estado americano, y preservar la integridad del sistema de protección a los derechos humanos establecido en la Convención Americana.

Los mecanismos tan distintos como podemos observar, para ejercer esta función en cada sistema, se reflejan tal vez en que el sistema europeo ha desaprovechado esta oportunidad de extender sus criterios a partir de la emisión de 
dichas opiniones. La facultad conferida relativa a funciones consultivas, en el tribunal europeo, "es mucho más reducida que la que se confiere a la Corte Interamericana" (Fix-Zamudio, 2008, pp. 203) y al día de hoy ha expresado tan solo dos opiniones consultivas, en cambio el sistema interamericano ha emitido veintiuna, que consideramos son de gran aportación. En ese orden de ideas, la Corte tal como lo declara en su opinión consultiva 14/1994:

[...] busca no solo desentrañar el sentido, propósito y razón de las normas internacionales sobre derechos humanos, sino, sobre todo, asesorar y ayudar a los Estados miembros y a los órganos de la OEA para que cumplan de manera cabal y efectiva sus obligaciones internacionales en la materia [...] se trata de interpretaciones que contribuyan a fortalecer el sistema de protección de los derechos humanos (Corte Interamericana, 1994, párr. 23).

\section{F. Las sentencias de ambos tribunales}

Respecto a las sentencias emanadas de ambos tribunales, hemos de analizarlas a partir de las reparaciones que acarrean, en el supuesto de la declaración de responsabilidad internacional a un Estado parte, y luego la ejecución de las mismas en el derecho interno.

Habremos de señalar que las sentencias de los tribunales en comento son definitivas y obligatorias, así lo disponen los artículos 67 y 68 de la CADH y los artículos 42 y 46 del Convenio Europeo; sin embargo, resulta complicado en algunas ocasiones que estos fallos sean eficaces per se, de ahí la urgencia de mecanismos que permitan lograr que las sentencias emanadas por estos tribunales necesariamente sean cumplidas por los Estados.

Sostiene Londoño que "una deficiencia común a los dos sistemas resulta ser la falta de un mecanismo regional unificado con miras a la ejecución de las sentencias de sus cortes en el plano interno del Estado condenado" (2005, p.
89). Aun así, creemos que el rol del Comité de Ministros tiene vigencia y es un elemento sin par en el sistema interamericano.

\section{Reparaciones en el ámbito internacional}

El sistema de reparaciones constituye uno de los principios fundamentales del derecho internacional de la responsabilidad de los Estados. Según García (2000) las reparaciones son el horizonte natural de las expectativas individuales y sociales en los casos contenciosos. Sin reparación, quedan firmes las consecuencias de la violación cometida.

En este aspecto debemos reconocer una divergencia entre ambos sistemas, en el sistema interamericano sin duda el esquema de reparación del daño es más amplio, en una comparación vis a vis al respecto, el artículo 63.1 de la Convención Americana reza:

Cuando decida que hubo violación de un derecho o libertad protegidos en esta Convención, la Corte dispondrá que se garantice al lesionado en el goce de su derecho o libertad conculcados. Dispondrá asimismo, si ello fuera procedente, que se reparen las consecuencias de la medida o situación que ha configurado la vulneración de esos derechos y el pago de una justa indemnización a la parte lesionada.

Frente al artículo 41 del Convenio Europeo que dice:

Si el Tribunal declara que ha habido violación del Convenio o de sus protocolos y si el derecho interno de la alta parte contratante solo permite de manera imperfecta reparar las consecuencias de dicha violación, el Tribunal concederá a la parte perjudicada, si así procede, una satisfacción equitativa.

Como se advierte en el caso europeo, el Convenio dispone que las reparaciones en dicho sistema sean subsidiarias, cuando el Estado no haya reparado (Salado, 2005). En cambio en el sistema interamericano, la Corte, de sus propias 
facultades convencionales y tal y como se desprende de su vasta jurisprudencia al respecto, ha otorgado medidas de desagravio para las víctimas de la violación de derechos humanos, desde la indemnización hasta medidas de satisfacción impuestas al Estado en virtud de tales o cuales hechos violados (García, 2003), sin hacer vínculo alguno a lo que en el derecho interno se haya resuelto en este asunto.

En el sistema interamericano la jurisprudencia es extensa al conceder un esquema de reparaciones en algunos de los casos que se someten a dicha jurisdicción, bien dicen, las medidas de reparación, en el ámbito interamericano, comprenden tanto aquellas que procuran garantizar que los hechos no se repitan (garantías de no repetición), como aquellas que buscan indemnizar económicamente los daños materiales y morales (medidas de compensación) (Cejil, 2004).

El sistema interamericano elaboró un concepto de reparaciones mucho más rico que el desarrollado por el derecho interno de la mayoría de los países del continente, en los que normalmente las reparaciones se agotan en el pago de una indemnización por los daños materiales y morales. En ese tenor podemos afirmar que el Convenio Europeo frente a todo el sistema de protección americano tiene un efectivo mecanismo para hacer cumplir las sentencias, "lo que se considera extraordinario del CEDH es la maquinaria para ejecutar las sentencias" (Janis \& Kay, 2008, p. 8).

Derivado del artículo 46 del Convenio Europeo, los Estados partes se comprometen a acatar las sentencias, situación que no debe ser sino justo la obligación que emana de adquirir compromisos internacionales y que creemos atiende al principio de pacta sunt servanda. No obstante, lo singular e importante en el sistema europeo a nuestro juicio en lo que a este punto se refiere, es lo que consigna en el inciso 2 del artículo 46 en comento: "la sentencia definitiva del Tribunal se transmitirá al Comité de Ministros, que velará por su ejecución".
En ese sentido, el tribunal europeo recoge un mecanismo de supervisión de sentencias más eficaz y claro que el sistema interamericano, incluso su artículo 46 establece supuestos en caso de incumplimiento. A pesar de ello, la recepción de las sentencias en el derecho interno, los Estados determinan suponemos, so pretexto de su autodeterminación, las vías legislativas o políticas para implementar las resoluciones del tribunal europeo.

De acuerdo con el principio pacta sunt servanda al que recién hicimos alusión, un Estado no puede invocar los preceptos de su derecho interno como justificación del incumplimiento de un tratado y este último no puede ser derogado, modificado o suspendido sino mediante las formas previstas en el tratado de que se refiere (Gómez-Robledo, 2009).

\section{Ejecución de sentencias}

Uno de los aspectos que diferencian al sistema europeo del interamericano y que resulta atractivo según Krsticevic (1998), es que el Consejo de Ministros supervise el cumplimiento de sentencias. Tratándose de la ejecución de fallos en el sistema interamericano, el artículo 68 de la Convención Americana llanamente expresa:

1. Los Estados partes en la Convención se comprometen a cumplir la decisión de la Corte en todo caso que sean partes. 2. La parte del fallo que disponga indemnización compensatoria se podrá ejecutar en el respectivo país por el procedimiento interno vigente para la ejecución de sentencias contra el Estado.

En cuanto al primer punto, la obligación convencional de los Estados miembros debería bastar para el cabal cumplimiento de la sentencia, sin embargo deja un "vacío" en la forma al menos convencional de cómo cumplirse, y de la misma forma que lo hace su homólogo europeo, plantea que aquello relativo a la indemnización compensatoria es ejecutable a través de los procedimientos internos (Krsticevic, 2007). 
Otro mecanismo de la Corte es el de la ejecución de las sentencias por medio de los tribunales nacionales del Estado. El artículo 68 inciso 2 de la Convención dispone, que la parte del fallo sobre indemnización compensatoria se podrá poner en marcha en el respectivo país, por el procedimiento interno vigente para la ejecución de sentencias.

Observamos en la práctica del tribunal americano, que frente al incumplimiento o retardo injustificado de los Estados en el cumplimiento de las sentencias, la Corte ha emitido resoluciones al respecto, como en los casos: Gelman vs. Uruguay, Vélez Loor vs. Panamá y Gómez Palomino vs. Perú, todos relativos a supervisión de cumplimiento de sentencia, entre otros. Incluso cimienta la emisión de estas resoluciones como una facultad inherente a sus funciones jurisdiccionales, sin que medie en nuestra opinión un fundamento expresamente estipulado en la Convención Americana. Aquella es una facultad implícita, aunque podemos asumir que atiende a esa carencia en los ámbitos convencional y procesal de darle seguimiento a una sentencia frente a el incumplimiento de un Estado o bien, de cara a la ausencia de un comité como lo sería el Comité de Ministros en Europa.

Para Buergenthal (2003) los Estados miembro de la Convención tienen la obligación en virtud del derecho internacional, de cumplir con una sentencia definitiva de la Corte en un caso en que sean partes, y en esos términos la propia Convención señala en su artículo 65 que:

La Corte someterá a la consideración de la Asamblea General de la Organización [...] un informe sobre su labor en el año anterior. De manera especial y con las recomendaciones pertinentes, señalará los casos en que un Estado no haya dado cumplimiento a sus fallos.

Por tanto, existe un mecanismo dentro del sistema para el cumplimiento de las sentencias aunado a lo que declara el artículo 41.g de la propia Convención y en este caso, a la obligación expresa de rendir informe a la Asamblea General de la
OEA. No obstante, como sugiere el autor en cita, se pueden desprender estas facultades, aunque el problema que enfrentan estas instituciones al buscar el cumplimiento de las sentencias de la Corte, es que tienen solo la competencia de adoptar recomendaciones y carecen de la facultad de imponer sanciones, lo cual de ninguna manera significa que el efecto político de una asamblea donde se concluya que un Estado no está cumpliendo con sus obligaciones convencionales es baladí.

La mera amenaza de tal supuesto puede en ciertas circunstancias lograr el cumplimiento. En este sentido, por supuesto, mucho depende de la voluntad política de los Estados miembros de la OEA. En el pasado demostraron poco entusiasmo para apoyar los esfuerzos de la Comisión o el Tribunal de insistir o "empujar" a los Estados morosos a cumplir con sus obligaciones relativas a la protección de derechos humanos (Buergenthal, 2003).

Existe pues una especie de control de ejecución de sentencias, como una herramienta precisamente para que estas resoluciones no sean tan solo declarativas y los Estados asuman con eficacia la probable responsabilidad internacional, "con ello el sistema interamericano afirma su especificidad frente al control político ejercido por el Comité de Ministros en el seno europeo" (Burgorgue-Larsen \& Úbeda, 2009, p. 42). En esos términos el artículo 46 del Convenio Europeo fija claramente en el título de dicho artículo lo relativo a la fuerza obligatoria y ejecución de las sentencias, y a partir de ahí establece entre otras cosas que

2. La sentencia definitiva del Tribunal se transmitirá al Comité de Ministros, que velará por su ejecución. 3. Cuando el Comité de Ministros considere que la supervisión de la ejecución de una sentencia definitiva resulta obstaculizada por un problema de interpretación de dicha sentencia, podrá dirigirse al Tribunal con objeto de que este se pronuncie sobre dicho problema de interpretación [...]. 
Pero incluso y esto a partir de la reforma del Convenio Europeo a través del Protocolo 14 (Queralt, 2010), en el artículo 31 del CEDH se dispuso que la Gran Sala: "[...] b) se pronunciará sobre las cuestiones sometidas al Tribunal por el Comité de Ministros de conformidad con el artículo 46, párrafo 4". De tal manera podemos aseverar que en el sistema europeo el esquema de ejecución de sentencias es mucho más diáfano y efectivo, claramente establecido en el Convenio, muy recientemente el Consejo de Europa publicó su reporte anual respecto de la supervisión conferida por el artículo 47 del Convenio Europeo ${ }^{7}$.

Sin duda, uno de los retos de los sistemas en cuestión, es la implementación de las decisiones judiciales en el derecho interno, vía reparación del daño (al menos en el sistema interamericano) o bien para ejecutar la sentencia, en cualquier caso, al margen de las obligaciones internacionales plasmadas en el escenario convencional, debe conseguirse esa efectividad en el derecho interno de las sentencias/jurisprudencia internacional.

\section{G. La influencia de la jurisprudencia del Tribunal Europeo en la Corte Interamericana: convergencias juris- prudenciales}

Un aspecto que consideramos poco se ha tratado y que es de gran trascendencia, es el que tiene que ver con la relación entre la jurisprudencia de ambos tribunales, es decir, el diálogo jurisprudencial que en efecto se presenta entre ellos. A pesar de las distintas realidades específicas de los dos continentes en donde funcionan, la Corte Europea y la Corte Interamericana han podido

\footnotetext{
El 10 de abril de 2013, el Comité de Ministros publicó su reporte anual sobre supervisión de ejecución de sentencias. Se reveló de dicho informe que el número de sentencias se ha reducido tratándose de casos repetitivos, al mismo tiempo la cifra de casos cerrados está aumentando. Lo que se atribuye está vinculado a varios factores, entre ellos la efectividad de los recursos domésticos que son parte integral de cada proceso de ejecución de sentencias.
}

establecer aproximaciones en sus jurisprudencias en la forma de abordar temas fundamentales... "la rica jurisprudencia sobre métodos de interpretación de la Corte Europea es una importante contribución histórica de la Corte Europea al derecho internacional de los derechos humanos en conjunto" (Cançado, 2007, p. 10).

Sendos tribunales han seguido una interpretación dinámica o evolutiva de las respectivas convenciones de derechos humanos (dimensión intertemporal), en ese sentido observamos casos concretos donde la Corte Interamericana recoge criterios jurisprudenciales del tribunal europeo, para ya sea fortalecer sus propios argumentos en su carácter de fuente interpretativa, o bien para ampliar la jurisprudencia. Por citar un ejemplo de ello, en el caso Kawas Fernández vs. Honduras la Corte Interamericana (2009) acopió los criterios del plazo razonable utilizado en el sistema europeo y definidos en algunas de sus jurisprudencias, tales como los casos Zimmermann y Steiner vs. España y Ruiz Mateos vs. España, entre otros; en general, la Corte Interamericana alude al homólogo europeo adoptando la interpretación que del mismo derecho ha hecho aquel.

Nos atrevemos a aseverar que ha sido la Corte Interamericana la que ha recogido en mayor medida, algunos criterios jurisprudenciales del tribunal europeo, para invocarlos y/o aplicarlos a los casos concretos del sistema interamericano. En el caso del sistema europeo, en menos ocasiones pero lo ha hecho, se ha referido a criterios jurisprudenciales de su homóloga interamericana.

En todo caso, ambas cortes "han logrado una construcción jurisprudencial notable con respecto al derecho al acceso a la justicia al nivel internacional" (Cançado, 2007, p. 19), y como se ha advertido con sus marcadas diferencias ambos tribunales han contribuido a una vasta interpretación de los derechos humanos en sendos continentes. 


\section{Conclusiones}

Los sistemas europeo e interamericano con sus divergencias y convergencias, se constituyen en promotores de derechos humanos en el ámbito internacional, se componen de dos tratados internacionales, Convenio Europeo y Convención Americana, que en su parte normativa crean en stricto sensu dos tribunales internacionales de derechos humanos y en el caso del sistema interamericano, una Comisión Interamericana de Derechos Humanos.

Tratándose de los derechos protegidos en ambos instrumentos identificamos más similitudes que diferencias, en esencia se protegen los mismos derechos humanos, aunque en el sistema europeo la "generación" de protocolos ha tenido un doble propósito, ampliar derechos pero también insertar cuestiones de procedimiento, contrario al sistema interamericano, que a través del Protocolo de San Salvador, se enfocó en el aumento de derechos económicos, sociales y culturales, el otro (abolición de la pena de muerte) tiene tal propósito.

Resulta primordial señalar que la otrora Comisión Europea sería el referente de la actual Comisión Interamericana, siendo la primera sustituida por el ius standi alcanzado en 1998 y que no tiene en este momento un par en el sistema interamericano. La Comisión Interamericana tiene un papel vital en el SIDH como órgano político, además de ser el escenario que remite asuntos a la Corte Interamericana.

En cuanto a los órganos jurisdiccionales de ambos sistemas, podemos decir que su gran diferencia es que la competencia contenciosa de la Corte Interamericana queda sujeta a la decisión del Estado, esto significa que son los Estados quienes determinan el reconocimiento (expreso) de este tribunal internacional, contrario al tribunal europeo donde todos aquellos Estados parte de la Unión Europea le componen.

No menos importante es reconocer que existe una influencia del tribunal europeo en la Corte
Interamericana, que se observa en la jurisprudencia interamericana que ha recogido en diversas ocasiones los criterios interpretativos de su homólogo europeo. En todo caso, convergencias y divergencias entre ambos las hay, sin duda en ese sentido se genera también un diálogo y logran sobre todo en sus propias estructuras formales y materiales, sumar a la protección de los derechos humanos en el plano internacional.

\section{Referencias}

Ambos, K. \& Böhn, M. (2013). Tribunal Europeo de Derechos Humanos y Corte Interamericana de Derechos Humanos. ¿Tribunal tímido vs. Tribunal audaz? En: E. MacGregor \& A. Herrera (eds.).

Diálogo jurisprudencial en derechos humanos (pp. 1.057-1.088). México D. F.: Tirant Lo Blanch.

Buergenthal, T. (2003). Implementation of the judgments. En: A. Cançado (dir.) Memoria del Seminario: El Sistema Interamericano de Protección de los Derechos Humanos en el Umbral del Siglo XXI (pp. 185-193). San José: Corte Interamericana de Derechos Humanos.

Buerguenthal, T. \& Douglas, C. (1998). The future of the Inter-American Human Rights System. En: F. Cox \& J. Méndez. El futuro del Sistema Interamericano de Protección de los Derechos Humanos (pp. 539-571). San José: Instituto Interamericano de Derechos Humanos.

Burgorgue-Larsen, L. \& Úbeda, A. (2009). Las decisiones básicas de la Corte Interamericana de Derechos Humanos. Pamplona: Civitas.

Cançado, A. (2001). Vers la consolidation de la capacité juridique internationales de pétitionnaires dans le système interaméricain de protection des droits de la personne. Revue Québécoise de Droit International, 14(2), pp. 208-239. 
Cançado, A. (2004). The Inter-American Human Rights System at the dawn of the new century: recommendations for improvement of its mechanism of protection. En: D. Harris \& S. Livingstone (eds.). The Inter-American System of Human Rights (pp. 395-420). Oxford: Oxford University Press.

Cançado, A. (2007). El desarrollo del derecho internacional de los derechos humanos mediante el funcionamiento y la jurisprudencia de la Corte Europea y la Corte Interamericana de Derechos Humanos. San José: Corte Interamericana de Derechos Humanos.

Centro por la Justicia y el Derecho Internacional (Cejil). (2004). Las reparaciones en el Sistema Interamericano de Protección de los Derechos Humanos. Cejil Gaceta.

Convención Americana sobre Derechos Humanos. (1969). Suscrita en San José de Costa Rica en la Conferencia Especializada Interamericana sobre Derechos Humanos, 7-22 de noviembre.

Convenio para la Protección de los Derechos Humanos y de las Libertades Fundamentales. (1950). Suscrito en Roma, 4 de noviembre.

Corte Interamericana de Derechos Humanos. (1982). "Otros tratados". Objeto de la función consultiva de la Corte (art. 64 Convención Americana sobre Derechos Humanos). Opinión consultiva de 24 de septiembre. Serie A-1.

Corte Interamericana de Derechos Humanos. (1994). Responsabilidad internacional por expedición y aplicación de leyes violatorias de la convención (arts. 1 y 2 Convención Americana sobre Derechos Humanos). Opinión consultiva de 9 de diciembre. Serie A-14.

Corte Interamericana de Derechos Humanos. (28 de junio de 2012). Caso Radilla Pacheco vs. Estados Unidos Mexicanos. Supervisión de cumplimiento de sentencia. Serie C.
Corte Interamericana de Derechos Humanos. (13 de febrero de 2013). Caso Vélez Loor vs. Panamá. Supervisión de cumplimiento. Serie C.

Corte Interamericana de Derechos Humanos. (13 de febrero de 2013). Caso Gómez Palomino vs. Perú. Supervisión de cumplimiento. Serie C.

Corte Interamericana de Derechos Humanos. (20 de marzo de 2013). Caso Gelmán vs. Uruguay. Supervisión de cumplimiento. Serie C.

Council of Europe. (2013). Supervision of the execution of judgments and decisions of the European Court of Human Rights. Annual report of the Committee of Ministers. Disponible en: http://www.coe.int/t/dghl/ monitoring/execution/sourcepublications/ cm_annreport2012_en.pdf

Díaz F. (2004). Jurisprudencia del Tribunal Europeo de Derechos Humanos. Lima: Palestra.

Díaz, F. (2011). Hacia una jurisdicción supranacional de los derechos humanos en Europa: luces y sombras en la experiencia del Tribunal Europeo de Derechos Humanos. En: U. Arzate \& P. Carrasco (coord.). Tendencias recientes de la justicia constitucional en el mundo. Ensayos escogidos. México D. F.: Universidad Autónoma del Estado de México, Universidad de CastillaLa Mancha.

Dondero, F. (2000). Sistema europeo e interamericano de protección de los derechos humanos. Similitudes y diferencias. Disponible en: http:/www.derecho.usmp.edu.pe/

Fix-Zamudio, H. (2000). The European and the Inter-American Courts of Human Rights: a brief comparison. En: P. Mahoney (dir.). Protecting human rights: the european perspective (pp. 507-533). Colonia: Carl Heymanns Verlag KG.

Fix-Zamudio, H. (2008). Reflexiones comparativas sobre los sistemas interamericano y 
europeo de protección de los derechos humanos. En: R. Méndez (dir.). Derecho internacional de los derechos humanos (pp. 203-290). México D. F.: Unam.

García, J. \& Santolaya, P. (2005). La Europa de los derechos. Madrid: Centro de Estudios Constitucionales de Madrid.

García, S. (2002). Los derechos humanos y la jurisdicción interamericana. México D. F.: Unam.

García, S. (2003). Las reparaciones en el Sistema Interamericano de Derechos Humanos. En: A. Cançado (dir.). Memoria del Seminario: El Sistema Interamericano de Protección de los Derechos Humanos en el Umbral del Siglo XXI, Tomo I (pp. 129-159). San José: Corte Interamericana de Derechos Humanos.

Gómez-Robledo, J. (2009). La implementación del derecho internacional de los derechos humanos en el derecho interno: una tarea pendiente. En: S. García (dir.). Recepción nacional del derecho internacional de los derechos humanos y admisión de la competencia de la Corte Interamericana de Derechos Humanos (pp. 127-150). México D. F.: Unam-SRE.

Janis, M. \& Kay, R. (2008). European human rights law, text and materials. Nueva York: Oxford University Press.

Krsticevic, V. (1998). Líneas de trabajo para mejorar la eficacia del sistema. En: F. Cox (dir.). El futuro del Sistema Interamericano de Protección de los Derechos Humanos (pp. 413-448). San José: Instituto Interamericano de Derechos Humanos.

Krsticevic, V. (2007). Implementación de las decisiones del Sistema Interamericano de Derechos Humanos. Jurisprudencia, normativa y experiencias nacionales. Buenos Aires: Cejil.

Londoño, M. (2005). Las cortes interamericana y europea de derechos humanos en perspectiva comparada. International Law, Revista
Colombiana de Derecho Internacional, 5 , pp. 89-115.

Nikken, P. (2003). La función consultiva de la Corte Interamericana de Derechos Humanos. En: A. Cançado (coord.). Memoria del Seminario: El Sistema Interamericano de Protección de los Derechos Humanos, Tomo I (pp. 161-184). San José: Corte Interamericana de Derechos Humanos.

Novak, F. (2002). El Sistema Interamericano de Protección de los Derechos Humanos: semejanzas y diferencias con el sistema europeo. La Comunita Internazionale Trimestrale della Societá Italiana per l'organizzazione Internazionale, LVII(4), pp. 649-681.

Ovey, C. \& White, R. (2002). The European Convention Human Rights. Nueva York: Oxford University Press.

Pastor, J. (2007). La protección jurisdiccional de los derechos humanos: una comparación entre el Tribunal Europeo y la Corte Interamericana. Revista Electrónica Iberoamericana, 1, pp. 5-14.

Protocolo Adicional a la Convención Americana sobre Derechos Humanos en Materia de Derechos Económicos, Sociales y Culturales. (1988). Protocolo de San Salvador, 17 de noviembre.

Protocolo 6. (1983). Convenio para la Protección de los Derechos Humanos y de las Libertades Fundamentales Relativo a la Abolición de la Pena de Muerte, 28 de abril.

Queralt, A. (2010). La protección de derechos y libertades en Europa tras la entrada en vigor del Protocolo 14 al CEDH. Revista Española de Derecho Europeo (REDE), 36, octubre-diciembre, pp. 487-520.

Robertson, A. (1981). The American Convention on Human Rights and the European Convention: a comparative study. Annuaire Européen, 29, pp. 50-76. 
Salado, A. (2005). Responsabilidad internacional por violaciones de derechos humanos. En: A. Salinas \& M. Vargas (coords.). Soberanía del Estado y derecho internacional, Tomo II (pp. 1.251-1.271). Sevilla: Universidad de Córdoba, Universidad de Málaga.

Secretaría de la Corte Interamericana. (2012). Documentos básicos en materia de derechos humanos en el sistema interamericano. San José: Corte Interamericana de Derechos Humanos.

Úbeda, A. (2007). Democracia y derechos humanos en Europa y en América, estudio comparado de los sistemas europeo $e$ interamericano de protección de los derechos humanos. Madrid: Reus.
Ventura, M. (2003). La Corte Interamericana de Derechos Humanos: camino hacia un tribunal permanente. En: A. Cançado \& M. Ventura (coords.). El futuro de la Corte Interamericana de Derechos Humanos (pp. 109-163). San José: Corte Interamericana de Derechos Humanos.

Viana, A. (2008). Sistemas europeo y americano de protección de derechos humanos. Coincidencias, fraccionamientos temporales y mutuas influencias. En: M. Revenga \& A. Viana (coords.). Tendencias jurisprudenciales de la Corte Interamericana de Derechos Humanos y el Tribunal Europeo de Derechos Humanos (pp. 16-69). Madrid: Tirant Lo Blanch. 